Results 326 STEMI patients were identified. Of these 12(3.7\%) declined investigation. 25(7.8\%) died during the investigation period (22 died during their initial acute event, 3 died of non cardiac causes following discharge). 10(3.1\%) requested follow-up in another geographical area. 26(8\%) patients were identified as LVEF $<35 \%$; $2(0.6 \%)$ patients were assessed as not clinically suitable for further investigation. 2(0.6\%) had $\mathrm{LVEF}<30 \%$ and $\mathrm{ORS}>120 \mathrm{~ms}$, both proceeded to have a primary prevention ICD implanted. $24(7.4 \%)$ patients had Holter monitors; $2(0.6 \%)$ were identified as having episodes of NSVT. Both patients had EPS; $1(0.3 \%)$ had inducible VT and proceeded to have a primary prevention ICD implanted. 1 patient $(0.3 \%)$ self presented with a cardiac arrest before completion of their screening tests and received a secondary prevention ICD. In total, $3(0.9 \%)$ primary prevention ICDs were implanted (Abstract 155 figure 2).

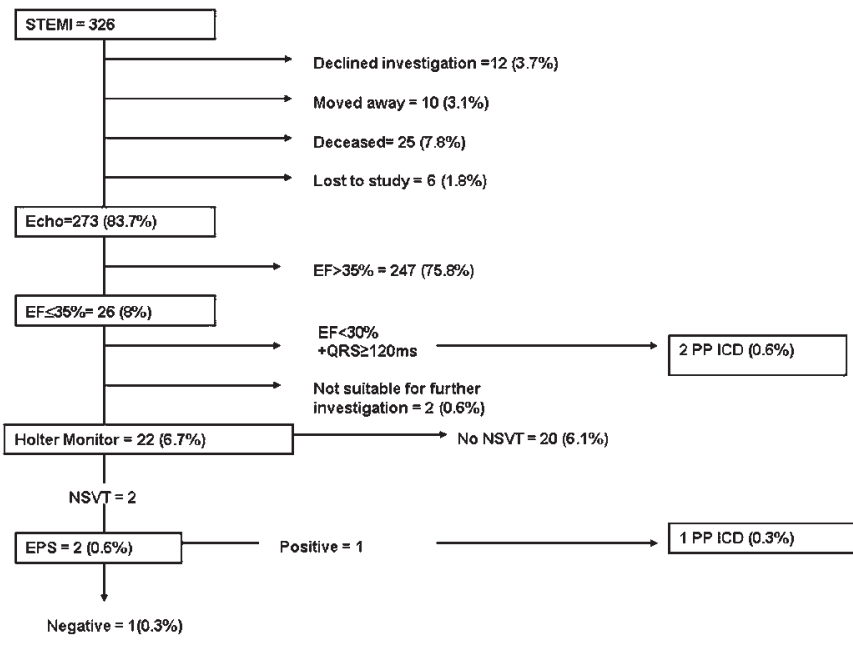

Abstract 155 Figure 2

Conclusion The yield from this study was low; 3 patients $(0.9 \%)$ proceeded to primary prevention ICD. It should also be noted that the methodology resultant from TA095 guidelines was labour and resource intensive. An alternative approach of opportunistic screening in patient groups with a high prevalence of impaired LV function might give a higher yield than our approach looking at disease incidence.

\section{A SINGLE CENTRE EXPERIENCE OF IVABRADINE AND CLONIDINE FOR INAPPROPRIATE SINUS TACHYCARDIA}

doi:10.1136/heartjnl-2011-300198.156

\section{P P Sadarmin, T R Betts. John Radcliffe Hospital, Oxford, UK}

Introduction Inappropriate sinus tachycardia (IST) is a relatively rare disease that manifests with resting tachycardia, a rapid increase in heart rate (HR) with minimal exertion, a normal ECG and absence of structural heart disease. Treatment options include $\beta$-blockade or sinus node modification which are not $100 \%$ successful. Newer agents like sinus node inhibitor (Ivabradine) or a centrally acting $\alpha-2$ sympathomimetic (Clonidine) can be used but there is no success outcome data for either and there is also no evidence that one is better than the other. We present our experience of managing 6 patients with a diagnosis of IST with either Ivabradine or Clonidine or both.

Methods We identified 6 patients from 2005 to 2009 with a diagnosis of IST (according to accepted international guidelines) who had been treated with either Ivabradine or Clonidine or both. Medical case records were reviewed for each patient.

Results 5 out of 6 patients were women with a mean age of 27.5 years (range $16-40$ years). All patients had been symptomatic for alteast 6 months before presentation to our tertiary centre. 2 patients had associated symptoms of hyperadrenergic surges. Holter monitoring prior to treatment demonstrated sinus tachycardia. Resting pre-treatment mean $24 \mathrm{~h} \mathrm{HR}$ was 94 10 (range 75-100) and mean HR on minimal exertion was 157 \pm 20 (range 130-176). All patients had a structurally normal heart on echocardiogram. Tilt table testing was considered in 3 patients due to their symptoms and it excluded postural orthostatic tachycardia syndrome. Pretreatment with $\beta$-blockers had been unsuccessful in $5 / 6$ patients. The remaining patient had symptomatic asthma and was therefore unable to tolerate $\beta$-blockers. Ivabradine was exclusively used in 3 patients and clonidine in 2.1 patient was started with Ivabradine but later switched over to clonidine as it was ineffective. All 4 patients taking Ivabradine failed to gain symptom relief with no significant reduction in mean $24-\mathrm{h}$ HR parameters. Mean resting HR after 3 months of Ivabradine therapy was $95 \pm 9$ (range 88-105) and mean HR on exertion was $159 \pm 23$ (range 128-180). 2/4 patients subsequently had complete sinus node ablation and AAIR pacemaker. In contrast, the 3 patients on clonidine had greater symptom resolution and fall in resting and exercise heart rates at 3 months follow-up. Resting mean HR was $81 \pm 3$ (range 78-83) and mean HR with exertion was $144 \pm 18$ (range 132-164). The HR variability pre and post treatment is shown in Abstract 156 figure 1 .

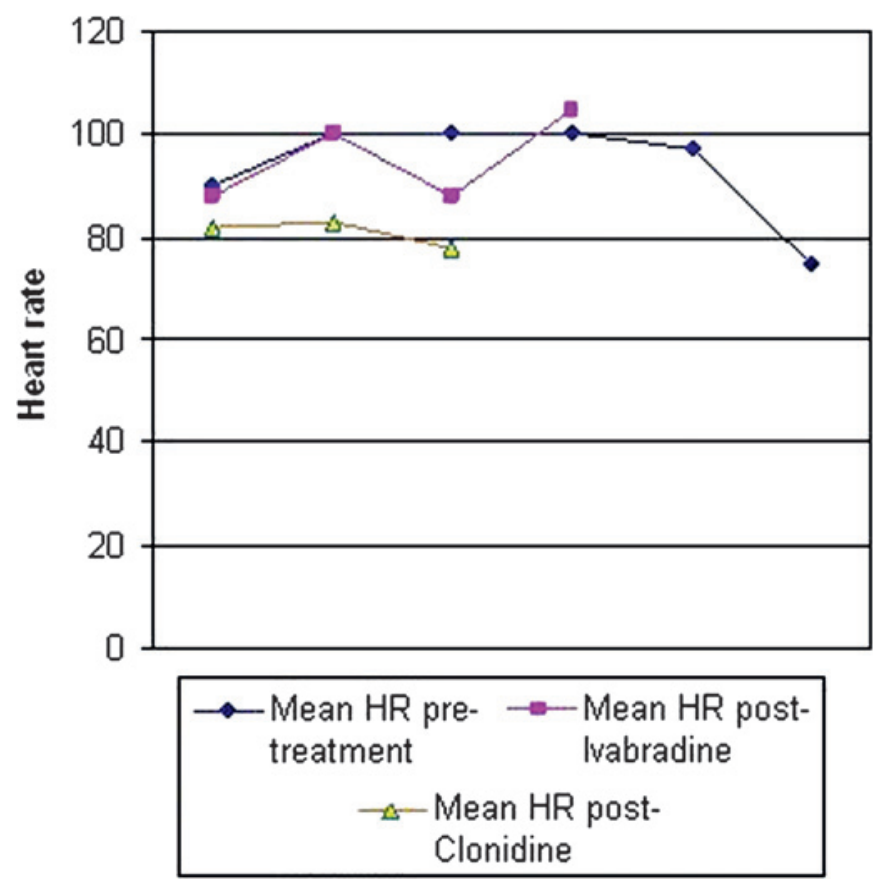

Abstract 156 Figure 1

Discussion In our case series of 6 patients, Clonidine was more effective than Ivabradine both in terms of reducing heart rate and treating symptoms for patients with inappropriate sinus tachycardia. Patients with coexisting hyperadrenergic symptoms may benefit the most. A trial of Clonidine can be recommended before considering sinus node ablation. Formal randomised controlled trials are needed to confirm our findings.

\section{AN INSIGHT INTO IMPLANTERS' PRACTICES OF ICD IMPLANTATION: A PHYSICIAN SURVEY}

doi:10.1136/heartjnl-2011-300198.157

P P Sadarmin, K C K Wong, K Rajappan, Y Bashir, T R Betts. John Radcliffe Hospital, Oxford, UK

Introduction The Implantable cardioverter defibrillator (ICD) is the mainstay of treatment for the prevention of sudden cardiac death (SCD) and the management of tachyarrhythmias. Informed patient 
consent is an essential part of the implant process. Our aim was to get an insight into implanters' (Imp) practices prior to an ICD implantation.

Methods A questionnaire survey was sent to UK ICD Imp to test their knowledge of the risk and benefits of an ICD in patients who satisfy trial and national guideline criteria and the incidence of implant complications. Information of the style and language of consent was requested. This questionnaire was specifically aimed at Imp and was part of the larger questionnaire looking at knowledge, attitudes and factors influencing ICD prescription in the UK.

Results Replies were received from 23 implanters. 35\% of the responders were between the age of 30-39 years and 39\% were between 40 and 49 years. $83 \%$ of the responders were Consultants and $96 \%$ were working in an implantating centre. $83 \%$ of Imp were fully aware of Primary Prevention (PP) NICE guidelines while $78 \%$ were fully aware of Secondary Prevention (SP) NICE guidelines. There was widespread use of information leaflets (87\%) and specialist ICD nurses (83\%) to disseminate information to patients. All responders said they would personally discuss the therapy with the patient prior to the implantation regardless of the referral source. A discussion regarding the prevention of SCD, inappropriate shocks and driving restrictions were performed by $96 \%$ of responders and device infections and lead failures discussed by $91 \%$. Use of absolute risk reduction in percentages and number needed to treat while explaining the risks and benefits gained from ICDs were used by $22 \%$ and $26 \%$ respectively. There was widespread use of phrases like "small risk" or "moderate risk" (61\%) and life prolongation (eg, lets you live longer by an average of 3 months) (30\%). Replies also indicated that Imp under-estimate overall mortality in medicallytreated and ICD-treated patients, lead dislodgement requiring re-positioning and major haematoma requiring reoperation. Imp overestimate infections leading to device removal and the incidence of pneumothorax when compared to published trial or study data.

Conclusion The majority of implanters are aware of UK ICD guidelines. The patient consent process is not universal. Guidelines and awareness about end-of-life care in ICD patients is needed and should be part of the initial consent process. Evidence based use of risk and benefit terminologies like ARR and NNT are needed to better inform the patient rather than abstract phrases. Increasing awareness of ICD complication rates can help patients and physicians balance risk against benefit which could lead to improved patient satisfaction with their therapy.

\section{Abstract 157 Table 1}

\begin{tabular}{|c|c|c|}
\hline $\begin{array}{l}\text { Estimate of ICD } \\
\text { complications }\end{array}$ & Mean \% & Published/Trial data \% \\
\hline $\begin{array}{l}\text { Death as a complication of } \\
\text { device implant }\end{array}$ & $0.37 \pm 0.48$ & $\begin{array}{l}\text { 0.77\% (Circulation.1998;98:663-670); } \\
2.08 \% \text { (Br Heart J.1995:73:20-24) }\end{array}$ \\
\hline $\begin{array}{l}\text { Lead dislodgement requiring } \\
\text { lead repositioning }\end{array}$ & $3.5 \pm 2.08$ & $\begin{array}{l}\text { 5\% (PACE.2005; 28:926-932); } \\
\text { 10\% (Circulation.1998;98:663-670) }\end{array}$ \\
\hline $\begin{array}{l}\text { Lead failure requiring extraction } \\
\text { or additional lead insertion }\end{array}$ & $5.4 \pm 7.28$ & 4.3\% (PACE.2005;28:926-932) \\
\hline $\begin{array}{l}\text { Major haematoma requiring } \\
\text { reoperation }\end{array}$ & $2.72 \pm 3.07$ & 5.8\% (JAMA.2006:295:1901-1911) \\
\hline $\begin{array}{l}\text { Device infection requiring } \\
\text { removal/extraction }\end{array}$ & $2.27 \pm 2.4$ & $\begin{array}{l}\text { 0.5\% (PACE.2005:28:926-932); } 0.77 \% \\
\text { (Circulation.1998;98:663-670);0.7\% } \\
\text { (MADIT2 trial) }\end{array}$ \\
\hline Cardiac tamponade & $0.7 \pm 1.07$ & $\begin{array}{l}0.2 \% \text { (PACE.2005;28:926-932); } \\
0.64 \% \text { (Circulation.1998;98:663-670) }\end{array}$ \\
\hline Pneumothorax & $1.68 \pm 1.17$ & $\begin{array}{l}\text { 1.1\% (PACE.2005; 28:926-932); } \\
0.89 \% \text { (Circulation.1998;98:663-670) }\end{array}$ \\
\hline Inappropriate shocks & $14.8 \pm 10.92$ & $\begin{array}{l}\text { 12\% (PACE.2005; 28:926-932); 14.91\% } \\
\text { (Circulation.1998;98:663-670); } \\
\text { 18\% (Z Kardiol.1996;85:809-819) }\end{array}$ \\
\hline $\begin{array}{l}\text { Psychological problems } \\
\text { associated with the device }\end{array}$ & $22.6 \pm 26.68$ & 13-38\% (Clin Cardiol 1999;22:481-9) \\
\hline
\end{tabular}

\section{IS IT COST EFFECTIVE TO USE A PLUGGED LV PORT?}

doi:10.1136/heartjnl-2011-300198.158

M A Jones, T R Betts, K Rajappan, Y Bashir, K C K Wong, N Qureshi. John Radcliffe Hospital, Oxford, UK

Background Many patients receiving ICD implants do not meet criteria for CRT therapy, yet are often felt likely to benefit from CRT in the future. The reasons for this include less severe NYHA class of HF symptoms at the time of implant, narrow ORS, and (progressive) atrio-ventricular conduction delay. Management options include only implanting DDD / VVI devices, and then upgrading to CRT if required; implanting CRT-D devices but without an LV lead, with the LV port "plugged", such that if an upgrade were to become necessary, only a new LV lead (and implant kit) would be required; and finally, implanting CRT-D devices with LV leads in all patients in the first instance, as has been suggested by the recent Madit-CRT and RAFT studies. It is not clear which of these strategies is superior in terms of the cost-benefit ratio.

Purpose This study analyses a retrospective cohort of patients who received CRT-D devices but without LV leads, to examine the cost implications of this approach, and to compare this cost to that of merely implanting a DDD device, or implanting a full CRT-D system initially. Method A retrospective analysis of all patients receiving CRT-ICDs with plugged LV ports between September 2004 and June 2009 at our institution. Patient characteristics, indication for a plugged LV port, subsequent addition of a LV lead and reasons for doing so were taken from patient records. The total cost (surgery and hardware) was compared with the estimated cost of initially implanting single or dual chamber ICDs and upgrading the entire system, and to the cost of implanting full CRT-D systems up front.

Results 35 patients (27 male) were identified. Mean (SD) age was $67 \pm 8$ years. 26 had ischaemic heart disease and 9 non-ischaemic dilated cardiomyopathy. All had LV EF $<30 \%$. Indications for a plugged LV port were LBBB and NYHA class I or II symptoms in 29 and NYHA class I or II with a narrow ORS but a high chance of becoming pacemaker dependent in 6. During a mean (SD) FU of $40 \pm 16$ months, $6(17 \%)$ patients had an LV lead added, all for the development of NYHA III symptoms, at 10, 11, 15, 17, 17 and 21 months respectively. Total cost at end of FU period was $£ 654000$. If all patients had initially been implanted with VVI or DDD ICDs and 6 new CRT systems implanted, the estimated cost would have been $£$ 598000 . If all patients had received full CRT-D the cost would have been $£ 665000$. Taking into account the time to develop symptoms, it is predicted that an upgrade rate of $26 \%-31 \%$ would be required before using a plugged LV port becomes cost-effective. Furthermore, full CRT-D system implantation is even less cost effective.

Conclusion In this series of ICD patients with potential CRT indications but minimal heart failure symptoms, only a small proportion subsequently required biventricular pacing. Using a CRT-ICD with a plugged LV port is not a cost effective strategy (Abstract 158 figure 1).

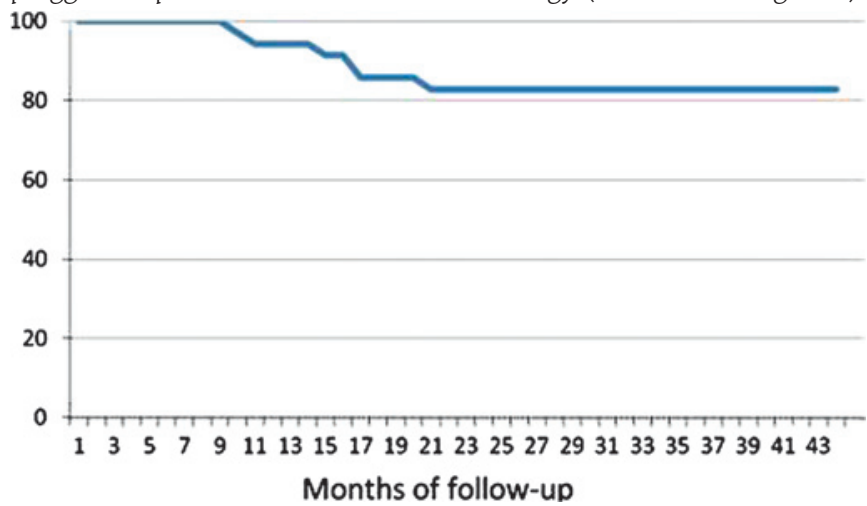

Abstract 158 Figure 1 Per cent freedom from upgrade to LV lead. 